con el propio Aristóteles ${ }^{8}$, quienes le advierten y aconsejan antes de emprender su camino, del mismo modo que Dios advierte a Adán en el Paraíso del tríptico bosquiano, antes de que desarrolle su caminar.

En la segunda parte del texto la Razón empieza a enfrentarse con el Rudo Entendimiento, que parece encontrar paralelo con la incomprensión de Adán y su desobediencia en el Paraíso. Por fin, a raíz de esto, el peregrino es acosado por la Pereza, la Soberbia, la Lisonja, la Envidia, la Traición, la Murmuración, la Ira, la Avaricia, la Gula, la Lujuria y la Herejía, siendo estas tres últimas las que presentan grabados más significativos. Además de la representación de cada una de las escenas grabadas es muy ilustrativo el texto, donde cada una de ellas habla de sus quehaceres y conexiones quedando en evidencia que responden al contexto iconográfico tradicional de cada una de ellas (Figs. 4-10).

Todo ello conduce al peregrino a la enfermedad y muerte pero, por su arrepentimiento, y temor de Dios, «la Gracia Divina» le asiste, terminando el autor con la consideración didácticomoralizadora, de que todas las tribulaciones del peregrino en su caminar, sirvan de prevención a los que comiencen este peregrinar (Fig. 11).

No cabe duda de que es el mismo mensaje del Bosco, aunque en el cuadro no se haya podido dar paso al lenguaje culto que aparece en el texto con la presencia de la Razón, etc. En el Bosco el final es menos esperanzador que en el libro, pero ambos finales se deben, sin duda, al comitente al que estuvieron destinados las dos ediciones del Peregrino de la Vida Humana y, al del Bosco que hasta ahora desconocemos ${ }^{9}$.

Isabel Mateo Gómez Dpto. H. ${ }^{a}$ del Arte del C.S.I.C.

y Julián Mateo Viñes

\title{
UN OBISPO DE LUGO EN SANTA CLARA DE TOLEDO: EL SEPULCRO DE FRAY JUAN ENRÍQUEZ
}

La controvertida atribución del sepulcro episcopal conservado en el convento de Santa Clara la Real de Toledo, provocó el olvido de un personaje, Juan Enríquez, obispo de Lugo, que se halla fuertemente vinculado a dicha comunidad, a pesar de haber ejercido su actividad como prelado en una sede lejana a ese centro. No resulta extraño el que un obispo franciscano se inhume en un convento de clarisas, dada la común pertenencia a una orden mendicante, pero además, en el caso del obispo Juan Enríquez, existen motivos que justificarían la elección de un espacio en el mismo, y además en un emplazamiento preferente como es el coro. Entre éstos, cabría conceder prioridad, como se verá, a la autoridad moral de este obispo de origen franciscano dentro de la Orden. Sus vínculos con las clarisas toledanas, han de ser complementados con los datos que la propia genealogía del prelado aporta, ya que, varios descendientes de un tronco común que parte de Alfonso XI, se inhuman en ese convento, al que no por azar se adjudica el calificativo de real, pues dos de las hijas bastardas de Enrique II alcanzaron en él la condición de abadesas (cuadro 1).

8 La presencia de Aristóteles y la Razón tan en conexión con la Summa hace pensar que los dos autores o por lo menos el francés pueda ser de la Orden de Predicadores.

9 Buzzati, loc. cit., nota 1, de la noticia de que se ha relacionado con Cebete, un filósofo místico cuatrocentista. 
Asimismo cobra valor de referencia para identificar el enterramiento. la propia imagen yacente, que muestra en un plano destacado, el cordón característico de la orden franciscana. Sin duda, las reiteradas estancias de Juan Enríquez en Toledo, antes y después de su nombramiento como obispo, le llevarían a un contacto con un taller importante: el de Ferránd González -muy activo en ese momento en la ciudad, tanto en la catedral como en diversos conventos- al cual pudo haber encargado su monumento funerario.

En lo que atañe a la autoridad de Juan Enríquez sobre la comunidad de clarisas de Toledo, existe un documento de 1395 en el que aparece como Visitador de las clarisas de Toledo y Guadalajara y Custodio de la Custodia de Toledo ${ }^{1}$. A ello es preciso añadir que en una bula del 8 de junio de 1417 fue nombrado junto al obispo de Jaén, Rodrigo Fernández de Narváez, y el deán de Toledo, conservador de los derechos de las clarisas de Toledo ${ }^{2}$. Sin embargo en los años que median entre ambas fechas, su biografía está jalonada de acontecimientos que lo vinculan con las más altas esferas de poder lo cual va a condicionar su dedicación y posibilidades de atención a las clarisas. Así, además de su estrecha relación con Enrique III, de quien fue confesor y testigo en el momento de dictar sus últimas voluntades ${ }^{3}$, y su condición de maestro en Teología, también ocupará el puesto de Ministro Provincial de los frailes menores de la provincia de Castilla ${ }^{4}$. Ante tal pluralidad de actividades, el propio Juan Enríquez se dirige al papa, exponiéndole que, dada su misión como confesor del rey, se veía inmerso en la solución de los conflictos que el cisma planteaba entre el monarca y la Santa Sede, lo cual le obligaba a desplazarse a la Curia pontificia; Benedicto XIII responde mediante una bula con fecha 1 de septiembre de 1406, indicándole que puede designar a otro religioso que le sustituya en el cargo de ministro provincial y visitador, para que él se ocupe de los otros asuntos. Pero él no pierde su condición de tal, como se aprecia en una bula de $1417^{5}$. Por otra parte, el 3 de julio de 1409 fue promovido al obispado de Lugo ${ }^{6}$, sede que ocupará hasta su fallecimiento en noviembre de 1418. No obstante, su actividad pastoral en Lugo no le impidió mantener el contacto con Toledo a donde acude en $1415^{7}$. No se sabe si permaneció allí mucho tiempo, pero es posible pensar que su fallecimien-

1 En él defiende a las monjas a las que se había impuesto una contribución de la que estarían exentas en virtud de sus privilegios: véase López, Atanasio: "Confesores de la familia real de Castilla», en Archivo Ibero-Americano, n. ${ }^{\circ 31}, 1929$, p. 40.

2 Reg. Vat. ser. Avin. t. 349, f. 303. Recogido en Bullarium franciscanum, tomo VII, n. ${ }^{\circ} 1162: 1417$, iunii 8, Paniscolae: Abbatissae et monialibus mon. Clarris. Toletan. episcopus Giennen. et Lucen. ac decanum ecclesiae Toletan. concedit conservatores iurium et privilegiorum ipsarum / Dilectis filiis Giennen. et Lucen. episcopis ac dilecto filio decano ecclesiae Toletan / Militanti ecclesiae etc. Datum Paniscolae Dertusen. dioec. Vl idus iunii anno vicesimo tertio.

3 Enrique III había dictado su testamento el 24 de diciembre de 1406 en su presencia, la de Fenando de Illescas, también franciscano y confesor real, y la de Pablo de Santa María, entonces obispo de Cartagena, entre otros; véase Arco, Ricardo del: Sepulcros de la casa real de Castilla, C.S.I.C., Instituto Jerónimo Zurita, Madrid 1954, p. 325.

4 Como indica la bula que le dirigió Benedicto XIII, el 11 de agosto de 1405, dándole facultad para recibir un convento que se pretendía fundar para los franciscanos, López, Atanasio, op. cit, p. 51. Tal como se recoge en el Bullarium franciscanum, tomo V11, n. ${ }^{\circ}$ 991, p. 338, el pontífice se dinge a Juan Enríquez como "Dilecto filio provinciali ord. fratr. Min. provinciae Castellae secundum morem ipsius ordinis».

5 «...quo dilectus filius Ioannes Henrici, minister provincialeis fratrum ord. Min. provinciae Castellae secundum instituta ordinis praedicti, magister in theologia et familiaris noster...", en Bullarium franciscanum, tomo VII, n. ${ }^{\circ} 1019^{\mathrm{a}}$, p. 349.

6 Tras el fallecimiento del dominico Juan de Feijoo como se recoge en la bula Apostolatus officium: Reg. Vat. ser. Avin. t. 332, f. 141, recogido en Bullarium franciscanum, tomo VII, n. ${ }^{\circ}$ 1078: 1409, iulii 3, Perpiniani: Ioannem Henrici ord. Min., mag. in theol., ecclesiae Lucen. (Lugos in Hispania) praeficit in episcopum / Dilecto filio Ioanni Henrici electo Lucen. / Apostolatus officium etc. Dudum diquidem etc. Postmodum vero ecclesia Lucen. per obitum b.m. Ioannis episcopi Lucen., qui apud sedem praedictam (apostolicam) diem clausit extremum, vacante, nos ad provisionem ipsius ecclesiae... intendentes... demum ad te ordinis fratrum Minorum professorem, magistrum in theologia, ... convertimus aciem nostrae mentis. Quibus omnibus debita meditatione pensatis de persona tua... praefate ecclesiae providemus teque illi praeficimus in episcopum et pastorem etc. Datum Perpiniani Elnen. dioec. V nonas iulii anno quintodecimo. / In e.m. capitulo et vassallis ecclesiae Lucen., clero ac populo civ. et dioece. Lucen, archiepiscopo Compostellan., Ioanni regi Castellae et Legionis.

7 Figura en un documento de aforamiento hecho en dicha ciudad, con fecha del 2 de enero; véase López, Atanasio, op cit., pp. 54-6. 
to, que Eubel sitúa el 28 de noviembre de 1418, hubiese tenido lugar en Toledo, y en concreto en el convento de clarisas donde será inhumado. Si bien desconocemos su testamento, se sabe que dejó una parte considerable de sus bienes al convento de Santa Clara de Toledo ya que existe una primera bula de Martín V aprobando, para tranquilidad de las monjas, los legados hechos a éstas por el prelado lucense ${ }^{8}$, que se complementa con una segunda ${ }^{9}$ en la que se indica textualmente: «in earum monasterio defunctus» ${ }^{10}$, lo cual corrobora la hipótesis de que Juan Enríquez es el prelado que se halla inhumado en el coro del convento y cuyo sepulcro ha llegado hasta nosotros.

Por lo que respecta al segundo aspecto, sobre los vínculos familiares del prelado lucense con el convento de clarisas de Toledo, baste recordar que Juan Enríquez, era hijo del Almirante Alonso Enríquez quien, a su vez, era nieto de Alfonso XI y Leonor de Guzmán, e hijo del maestre de Santiago y señor de Haro, Fadrique, hermanastro de Pedro I y hermano de Enrique II; como se observa, estaría directamente entroncado con la monarquía castellana.
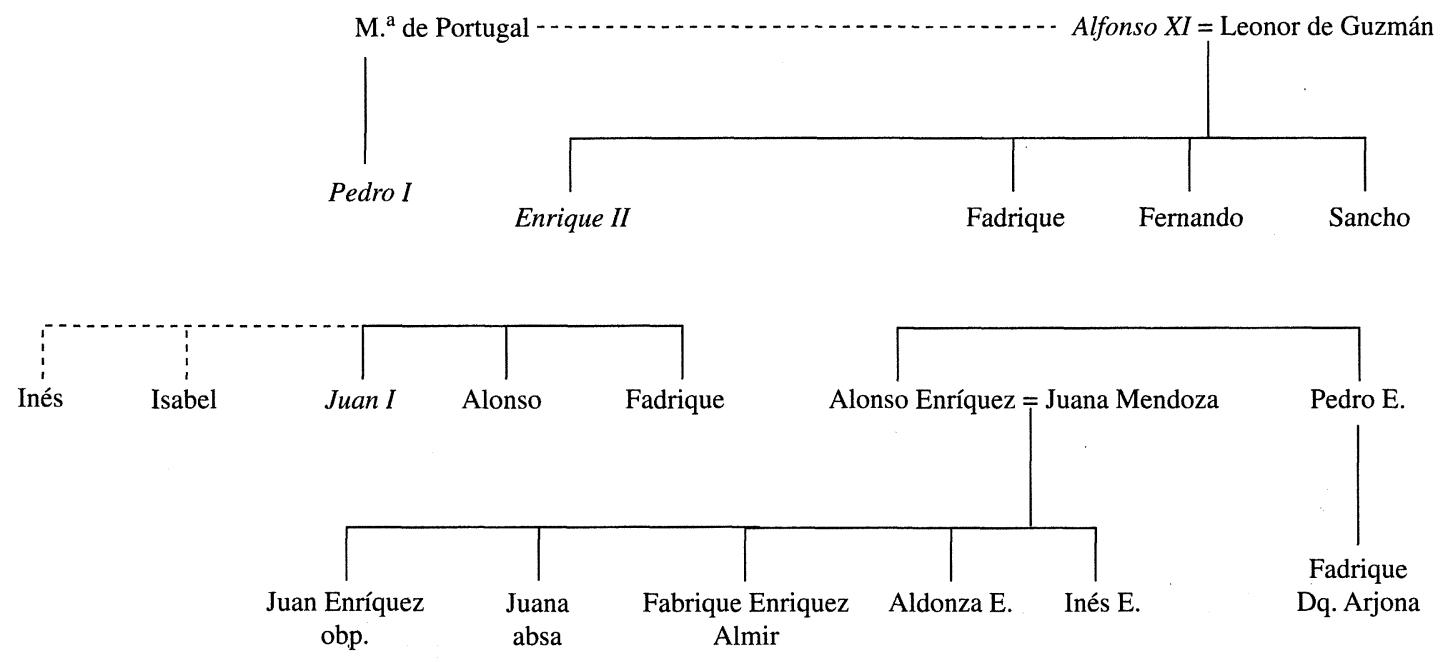

8 Reg. Vat. ser. Lat. t. 203, f 287; conf. 1078 y 1430, recogido en Bullarium franciscanum, tomo VII, n. $^{\circ} 1400: 1418$ decembris 18, Mantuae: Thesaurarium ecclesiae Toletan. quoddam legatum per Ioannem episcopum Lucen. (ex ord Min.) monasterio Clariss. Toletan. factum confirmare iubet / Dilecto filio thesaurario ecclesiae Toletan / Humilibus supplicum votis etc. Exhibita siquidem nobis pro parte dilectarun in Christo filiarum Agnetis abbatissae et conventus monasterii s. Clarae Toletan. ordinis eiusdem sanctae petitio continebat, quod olim bo. me. Ioannes episcopus Lucen., etiam professor ordinis fratrum Minonum existens, in suae ultimae voluntatis testamento nonnulla tunc expressa reset bona mobilia, ad ipsum legitime spectantia, eisdem abbatissa et conventus praedictae (in vim donationis, legationis et assignationis eorundem) possessionem apprehendentes, illa ex tunc tenuenunt, prout tenent pacifice et quiete. Quare pro parte dictarum abbatissae et conventus nobis fuit humiliteer supplicatum, ut donationem, legationem et assignationen praedictas apostolico roborare munimine... dignaremur. Nos igitur, qui de praemissis certam notitiam non habemus, ... discretione tuae... mandamus, quatenus, si est ita, donationem, legationem et assignationem praedictas, in quantum rationabiliter eas factas fore inveneris, et quaecunque inde secuta, auctoritate nostra approbes et confirmes. Datum Mantuae XV kal. ianuarii anno secundo.

9 Dada tras la sentencia de excomunión que, Fernando de Palacios, su sucesor en la sede de Lugo, había impuesto a cuantos habían tenido participación en los bienes legados por Fray Juan Enríquez.

10 Recogida en Bullarium franciscanum, tomo VII, n. ${ }^{\circ}$ 1430, pp. 527-8: 1419, octobris 30, Florentiae: Thesaurario ecclesiae Toletan. mandat, ut, cum Fernandus episcopus Lucen. in omnes, qui aliaqua bona per Ioannem episcopum Lucen., eius antecessorem, relicta, nisi ea infra certum temporis terminum restituerent, sententiam excomm. tulit, Agnetem abbatissam et conventum mon. Clariss. Toletan., quibus ipse Ioannes episcopus (ex ord. Min.), in earum monastetio defunctus, in sua ultima voluntate quaedam pecuniarum summas aliaque bona reliquit, licet credant se ea tamquam, canonice relicta retinere posse, ad cautelam ab illa sententia absolvat. / Dilecto filio thesaurario Toletam Humilibus supplicum votis etc. Datum Florentiae III Kal. novembris anno secundo. 
Conviene tener presente asimismo, que en el convento de clarisas de Toledo fueron abadesas las infantas Inés e Isabel, hijas naturales de Enrique II ${ }^{11}$. Ambas se hallan inhumadas a los pies del altar del coro bajo laudas de piedra negra ${ }^{12}$. Por su parte, tras el óbito de Inés, según indica un documento de 1447, la abadesa sería Juana, hija del conde Alfón, sobrina de las Infantas. En efecto, sus padres fueron Alfonso Enríquez y Juana de Mendoza, la "Rica Hembra», datos que coinciden con los del prelado de quien por consiguiente podemos considerar hermana. Esta se halla también inhumada en el coro junto a las infantas, aunque un epígrafe del siglo xVIII la llama María:

«FUNDARON ESTE COMB ${ }^{\text {TO }}$ LAS SEÑORAS YNFANTAS $D^{\mathbb{N}}$ YNES Y ${ }^{\mathbb{N}}$ YSABEL, HIJAS DEL REY D. ENRIQUE, Y UNA SOBRINA LLAMADA DONA MARIA; ESTAN LAS TRES Y EL DUQUE DE ARJONA, SU TIO, ENTERRADOS DELANTE DEL ALTAR MAYOR. ACAVOSE LA OBRA EL ANO DE 1406, SIENDO ABADESA LA SA D $^{A}$ YNES, Y SE HIÇO EL CIELO RASO EL AÑO DE 1794. SIENDO ABAD LA S ${ }^{A} D^{A}$ MARIA JOSEFA DE TOVERA» ${ }^{3}$.

Pese a los errores en los que incurre este epígrafe, ya que la fundación es anterior a las infantas, y cambia el nombre de la abadesa Juana, para nuestro objetivo proporciona un dato de sumo interés, como es la identificación del personaje que, bajo una cuarta lauda, se halla inhumado en el coro. Se trata del duque de Arjona, Fadrique, conde de Trastámara -como su padre Pedro Enríquez, hermano de Alfonso Enríquez- por lo que, el allí inhumado, sería primo de la abadesa Juana y, por lo mismo, del obispo Juan Enríquez. Aunque carece de inscripción, se puede apreciar un blasón en relieve con dos leones en el campo y en el cabo un castillo, tal como lo describe M. Castro ${ }^{14}$. Dicha descripción se ajusta a la que poseen las armas de su padre, según recoge F. Menéndez Pidal ${ }^{15}$.

En esencia, lo que en realidad encontramos en el convento de Santa Clara es un auténtico panteón familiar. Bien es verdad que el duque de Arjona había previsto en San Francisco de Lu-

11 En algunos documentos pontificios se hacen considerar legítimas, dándole incluso al convento el título de Real: véase Castro, Manuel de, OFM: «El convento de Santa Clara, de Toledo, según documentos de los siglos XIV y XV», en $B o$ letín de la Real Academia de la Historia, tomo CLXXIV, sept.-dic. 1977, cuad. III, pp. 503-4. En realidad primero debió obtener una dispensa del nuncio de Clemente VII puesto que era ilegítima, véase, Martínez Caviro, Balbina: «El arte mudéjar en el monasterio de Santa Clara la Real de Toledo", en Archivo Español de Arte, n. ${ }^{\circ} 181-4$, t. XLVI, 1973, p. 373. Inés es designada como abadesa en 1393, falleciendo hacia 1443; junto a ella, también figura como abadesa, su hermana Isabel, quien debió morir en tomo a 1420 o 21, según Martínez Caviró, id., p. 374, lo cual es reiterado por Castro, M., op. cit., p. 498, y por ella misma en su libro Conventos de Toledo. Toledo, castillo interior, Edic. El Viso, Madrid 1990, p. 188. Según recoge Arco, Ricardo del, op. cit., p. 313, la infanta Isabel había estado casada en secreto con Gonzalo Núñez de Guzmán, por lo que el rey lo hizo prisionero y sólo lo soltó tras tomar el hábito de la orden de Alcántara, entrando ella como religiosa en Santa Clara de Toledo.

12 En la de Isabel se puede leer: "AQUI YACE LA SENNO/RA DONNA YSABEL HIJA DEL REY DON ENRIQUE DE B/UENA MEMORIA FA/ LLECIO ANNO DE MILL E CCCC...». Martínez Caviro, Balbina: «El arte mudéjar...», op. cit., p. 385, nota 49.

13 Según recoge Martínez Caviro, B.: «El arte mudéjar...», op. cit., p. 386.

14 Castro, Manuel OFM., op. cit., p. 501.

15 Menéndez Pidal, Faustino: Heráldica medieval española. La casa real de León y Castilla, Hidalguía, Madrid 1982, pp. 112 bis y 142-3, indica que las armas del duque de Arjona se recogen en el sepulcro de su esposa Aldonza de Mendoza. No obstante, tal como se puede observar el escudo del duque de Arjona en el castillo de Ponferrada, existen ciertas variantes, pues en éste aparecerían los palos de los Trastámara, vibrados, mientras en el caso de su padre serían ondeados. Realmente los palos no están presentes en los dibujos que aporta F. Menéndez Pidal. Por su parte, el escudo de Ponferrada está recogido en, Pardo de Guevara y Valdés, Eduardo: El condado de Lemos en los siglos XIV y XV. De los "Comes Gallicae» a los Reyes Católicos, Tesis doctoral presentada en el Departamento de Paleografía y Diplomática de la Facultad de Geografía e Historia de la Universidad Complutense de Madrid, 1984, p. 173. Agradezco a su autor el haberme permitido su consulta. 
go, el panteón para su linaje ${ }^{16}$. Sin embargo, él mismo, tras su fallecimiento en Peñafiel -marzo de $1430{ }^{17}$ - donde se hallaba prisionero debido a las intrigas de Alvaro de Luna, tuvo sus exequias en Santa Clara de Astudillo ${ }^{18}$, y fue en un principio sepultado en el monasterio de Benevivere donde existió su epitafio ${ }^{19}$. Posterior sería su traslado a Santa Clara de Toledo, donde fue sepultado en el coro junto a sus parientes antes citados ${ }^{20}$.

Sin embargo, la atribución de este sepulcro episcopal ha resultado muy controvertida, ya que su propia ubicación -empotrado bajo un arcosolio a cierta altura del coro-impedía observar ciertas características que hoy no dejan lugar a la duda. Restaurado en 1993, se encuentra en la actualidad en medio del coro, exento, tal como habría sido su planteamiento originario, según se aprecia en su talla por las cuatro caras ${ }^{21}$.

Varios autores se han referido a este sepulcro identificándolo con diversos personajes ${ }^{22}$. En nuestra opinión, la documentación anteriormente mencionada, así como las relaciones de pa-

16 En él, como ha indicado Núñez, se hallarían su padre -el ya citado Pedro Enríquez, al que podría corresponder uno de los sepulcros conservados-, su madre, Isabel de Castro, y dos de sus hermanos, Enríque Enríquez y Constanza de Castro; Núñez Rodríguez, Manuel: La idea de inmortalidad en la escultura gallega, Diputación Provincial de Orense, Orense 1985 , pp. 133-7.

17 La fecha es discutida; así, mientras Núñez Rodríguez, M.: La idea..., op. cit., p. 134 indica que el fallecimiento tuvo lugar el 20 de marzo, Martínez Caviro, B.: “El arte mudéjar...», op. cit., p. 385, nota 46 señala que la muerte fue el día 22.

18 El rey que estaba en dicha localidad «se vistió de paño negro e lo truxo nueve días por el debdo que con él había, e mandó hacer sus obsequias en el Monasterio de Santa Clara de Astudillo muy honorablemente», Pardo de Guevara y Valdés, E., op cit., p. 210.

19 «Aqui yace el muy esforzado caballer / D. Fadrique de Castro, Duque de Arjona. / Traxolo a esta casa pero Ruiz Sarmiento / primer conde de Salinas, su sobrino / murió en el castillo de Peñafiel en prisión. Año MCCCCXLII" / Véase Pardo de Guevara y Valdés, E., op. cit., pp. 209-10. Un epitafio más breve que aporta Castro, M.: «El convento...», op. cit., p. 502, indica como año del fallecimiento 1432: Aquí yace el esforzado caballero D. Fadrique de Castro, duque de Arjona. / Murió en el castillo de Peñafiel en prisión, año 1432».

20 Por su parte, su esposa, Aldonza de Mendoza, se inhumó en el monasterio de Lupiana (Guadalajara), caso peculiar que ha sido objeto de estudio por parte de Núñez, quien lo ha relacionado con las problemáticas relaciones entre ambos cónyuges, sin que ello impida que tanto en el epitafio como en la heráldica, esté presente el recuerdo del marido: Núñez Rodríguez, Manuel: «La dama, el matrimonio y la fama póstuma», en Parentesco, familia y matrimonio en la Historia de Galicia, Tórculo, Santiago, de Compostela 1989. Es preciso recordar el romance de este daque de quien entre otras cosas se decía: / "...De vos, el Duque de Arjona / grandes querellas me dan / que forzades las mujeres / casadas y por casar».

21 La duda sobre su condición de sepulcro exento y su situación ya había sido planteada por Martínez Caviro, Balbina: "El mudéjar...», op. cit., p. 384, debido a la existencia de algunos fragmentos sueltos de alabastro tallado, y por Franco Mata, M. Angela: "El sepulcro de Don Pedro Suárez III (s. XIv), y el taller toledano de Ferrand González», en Boletín del Museo Arqueológico Nacional, vol. IX, n. ${ }^{\circ}$ 1-2, Madrid 1991, p. 100, para quien la colocación invertida del can y la ubicación del sepulcro en un lugar innacesible le hacían pensar que no se encontraba en su emplazamiento primitivo.

22 Es significativa su omisión por parte de Quadrado, José María y Fuente, Vicente de la: España. Sus monumentos y artes. Su naturaleza e Historia, Castilla la Nueva, tomo III: «Toledo y Ciudad Real», Establecimiento Tipográfico-Editorial de Daniel Cortezo y Cia., Barcelona 1886, quienes citan los restantes sepulcros de dicho convento. Ya en 1929 Atanasio López, consideraba que el obispo Juan Enríquez quizás hubiese muerto en Toledo, "siendo seguramente su sepulcro el que existe en el coro del convento de Santa Clara», López, Atanasio, op. cit., p. 56. Años más tarde -en 1973- Martínez Caviró se preguntaba quién podría ser el personaje allí inhumado, descartando al duque de Arjona pues la figura yacente posee mitra, y considerando la posibilidad de que se tratase del déan de Calahorra Velasco Hernández, "bachiller en Leyes», cuyo nombre aparece documentalmente vinculado al convento en alguna ocasión: Martínez Caviro, B.: "El mudéjar...", op. cit., pp. 384-5. Por su parte el franciscano Manuel de Castro en 1977, insiste en que, no es factible la atribución de Martínez Caviró, por la presencia de mitra, báculo y cordón franciscano, lo que apuntaría hacia el obispo Juan Enríquez. Pérez Higuera un año después, al estudiar los sepulcros del taller de Ferránd González, se refiere a éste como de un obispo, considerando la posibilidad de que se tratase de Juan de Illescas; Pérez Higuera, M. ${ }^{\text {a }}$ Teresa: «Ferrand González y los sepulcros del taller toledano (1385-1410)", en Boletín del Seminario de Estudio de Arte y Arqueología de la Universidad de Valladolid. Valladolid, 1978, pp. 129-142. La propia Martínez Caviró en 1980, siguiendo a Castro, lo identifica ya con Fray Juan Enríquez, ratificándose en ello en 1990; Martínez Caviró, Balbina: Mudéjar toledano. Palacios y conventos, Madrid, 1980, p. 334; Conventos de Toledo..., op. cit., p. 192. Esta misma atribución es indicada por Revuelta Tubino en 1983; Revuelta Tubino, Matilde (dir.): Inventario artístico de Toledo capital. Centro Nacional de Información Artística, Arqueológica y Etnológica, tomo I, Madrid, 1983, p. 55. Finalmente Franco Mata, recoge la opción de Juan de Illescas o Juan Enríquez sin decantarse por ninguna de ellas; Franco Mata, M. A., op. cit., p. 98. 
rentesco con otros personajes allí inhumados, demuestran que el sepulcro de Santa Clara de Toledo corresponde al obispo de Lugo, el franciscano Juan Enríquez.

Por lo que respecta a la cronología del sepulcro, tal como ha indicado Pérez Higuera al agrupar las diferentes obras correspondientes al taller de Ferránd González, se inscribira dentro de un tercer grupo realizado entre 1400 y 1410, opinión compartida por Franco Mata ${ }^{23}$. En efecto, su actividad episcopal se inició en dicho período, si bien casi al final de la década -el 3 de julio de 1409-, por lo que no sería posible una fecha anterior para el comienzo de su sepulcro en el que se le inmortaliza vestido de pontifical. Por consiguiente sería más ajustado considerar la realización de este sepulcro entre 1409 y 1418 año de su fallecimiento, teniendo además en cuenta que, a pesar de ocupar la sede lucense, existe constancia documental de su estancia en Toledo, al menos en 1415 , como ya se ha señalado.

En cuanto a su estilo, no cabe duda su adscripción al taller toledano de Ferránd González. Con él muestra numerosas afinidades de tipo iconográfico tanto en el yacente como en la peana y la utilización de leones como soporte (fig. 1), que lo aproximarían a conjuntos sepulcrales de otros prelados de la Castilla del momento como Pedro Tenorio, Diego de las Roelas, Vicente Arias Balbona o Juan Serrano.

Si se efectúa una aproximación de tipo iconográfico, se puede observar que la imagen yacente, de alabastro, descansa sobre tres almohadas decoradas con motivos geométricos y vegetales, que siguen trazos en cuadrícula y rematan en borlas que todavía conservan el dorado con que estaban cubiertas. Sobre ellas se apoya la voluta del báculo - la cual a modo de cordón encierra una cabecilla humana-, y la cabeza del prelado, que se cubre con la mitra bajo la que sobresale un corto flequillo, destacando los largos mechones de cabello recogidos tras las orejas. La mitra aparece minuciosamente decorada con granulado en el fondo, cuadrilóbulos que enmarcan cabecillas humanas y una cenefa que rodea la cabeza y la parte central con motivos circulares y cuadrados en relieve, imitando el engaste de piedras preciosas, por lo que se correspondería con una mitra Phrigiata, usada en las celebraciones más solemnes, y donde las piedras preciosas simbolizarían la caridad que deben tener los obispos ${ }^{24}$. Los bordes de todos esos motivos decorativos, conservan todavía parte del dorado. El báculo, está cubierto con el panisellum, y descansa bajo el brazo izquierdo; los pliegues de la casulla ocultan una gran parte del asta, de la que además se ha perdido el remate (fig. 2).

Su atuendo episcopal está representado de forma muy minuciosa, comenzando por el alba o túnica, a la que se superponen la sobrepelliz y la dalmática (fig. 3). Todo ello alcanza un efecto plástico que se aproxima incluso a calidades pictóricas patentes en los pliegues de remate de la vestimenta, más menudos y menos geométricos que los correspondientes a la casulla, realizada, por otra parte, con un tejido más grueso. Cabe destacar, asimismo, la utilización del cordón franciscano a modo de cíngulo, cuyo remate anudado, se puede apreciar sobre la túnica, constituyendo un elemento clave sobre la identidad del personaje (fíg. 4). Curioso contraste plantea este símbolo de austeridad y pobreza en un conjunto funerario que intenta subrayar el principio de autoridad, y calidad moral, mediante una gran riqueza plasmada, entre otras cosas, por medio de una casulla decorada en el pecho con una cruz ornamentada con tallos ondulantes, semejantes a los de la cenefa de la almohada, y a los que también adornan el cuello. Los bordes de la casulla se decoran mediante una red de rombos, motivo que se vuelve a apreciar en la estola, cuyos extremos, totalmente cubiertos de dorado, sobresalen bajo dicha vestidura y en el remate de los guantes litúrgicos. Estos reiteran la idea de magnificencia decorándose con un medallón en relie-

\footnotetext{
23 Pérez Higuera, M. T., op. cit., p. 139. Franco Mata, M. A., op. cit., p. 100.

24 Lobera y Abío, Antonio: El por qué de todas las ceremonias de la Iglesia y sus misterios, Imprenta de Higinio Reneses, Madrid, 1856, p. 68.
} 

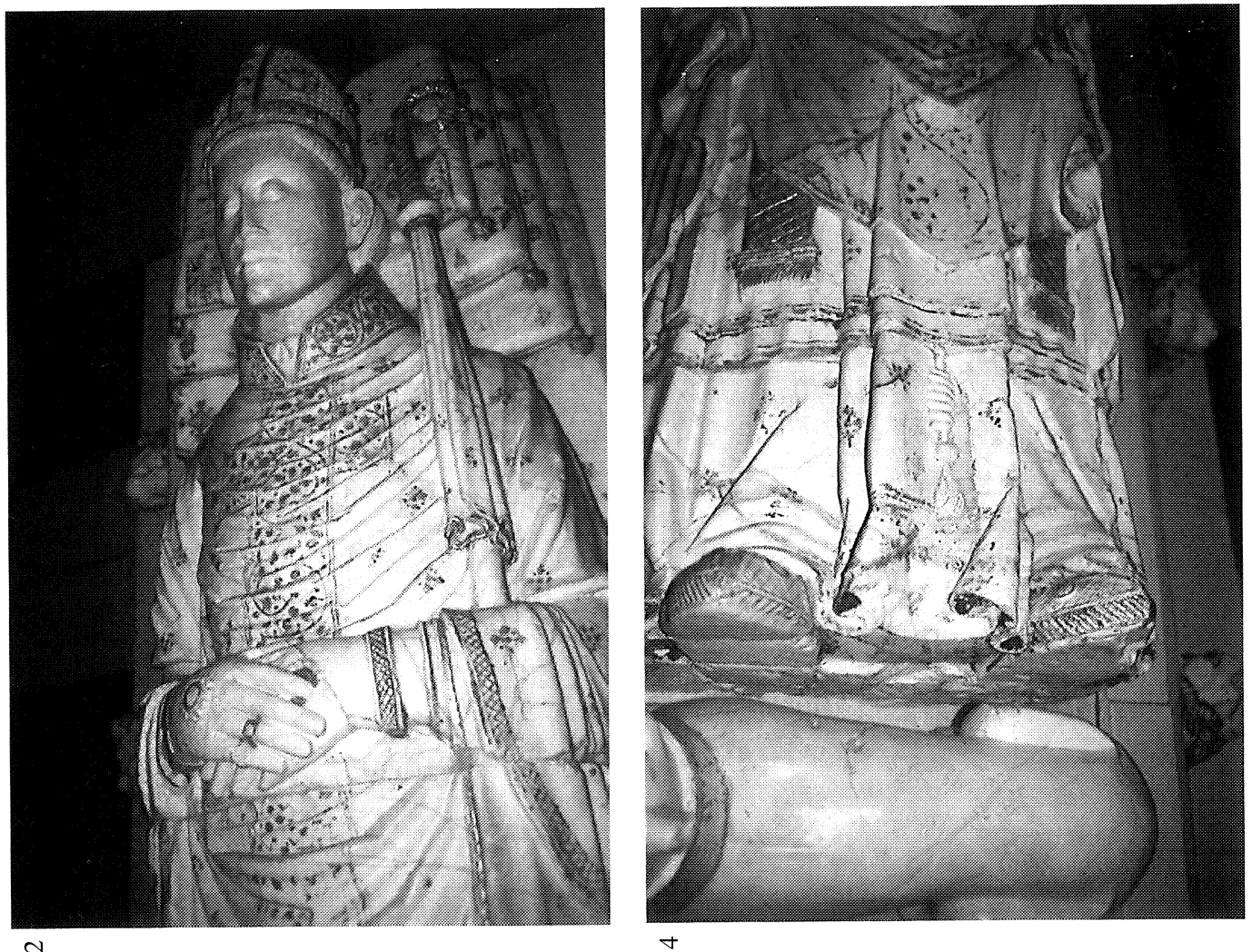

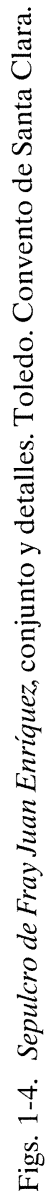
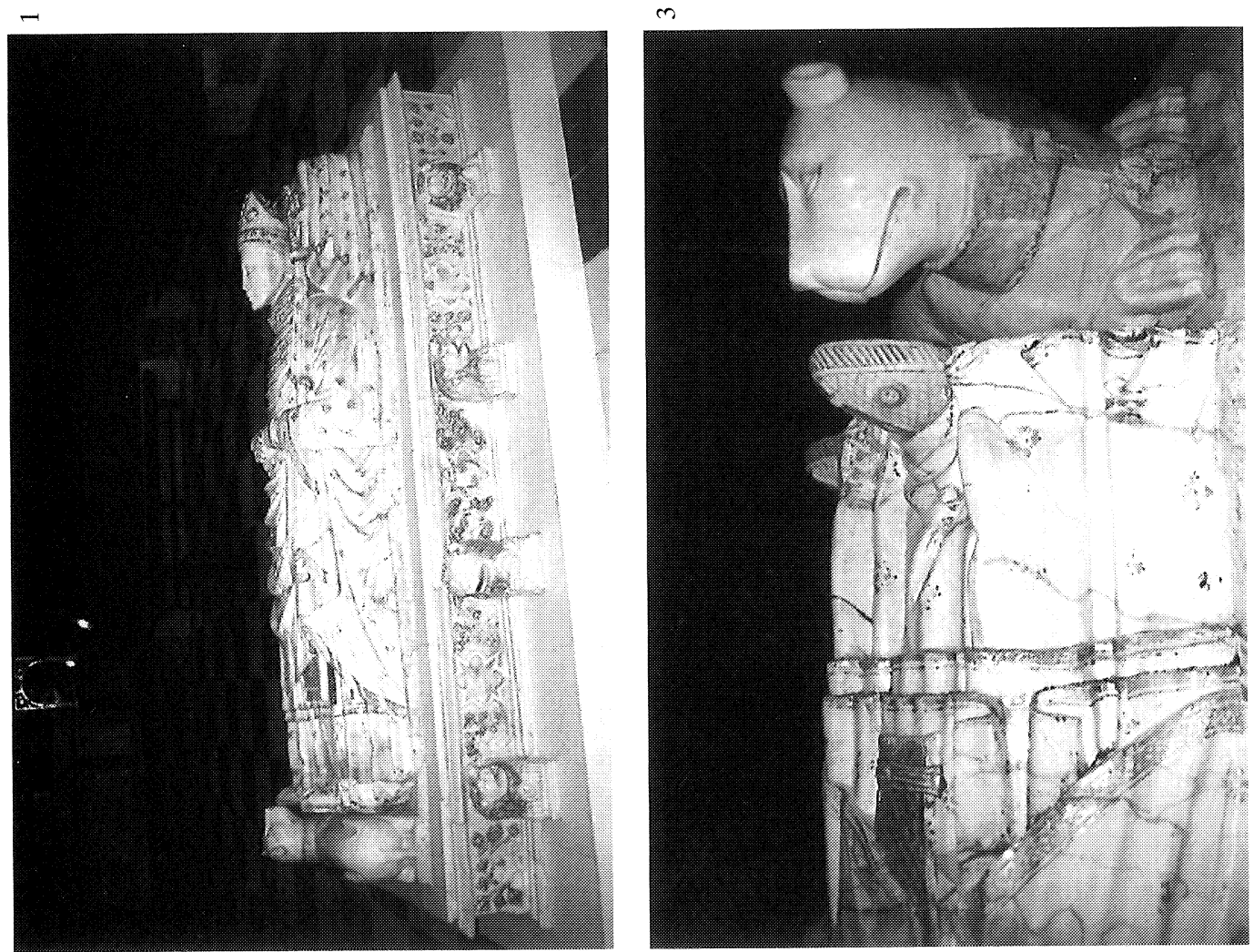
ve, rodeado por una orla perlada, y sobre ellos se coloca el anillo, en el dedo anular de la mano derecha, el cual constituía uno de los elementos fundamentales en la consagración episcopal y un verdadero símbolo de su poder.

Aunque no son tan claramente apreciables, destaca bajo el cuello el amito, así como el manípulo que cuelga sobre la mano izquierda, rematando con fleco dorado. Finalmente habría que destacar las sandalias bordadas con aljófar, y con motivos en relieve semejando piedras engastadas.

En lo que atañe a su posición, el obispo cruza sus manos sobre el vientre, situando la derecha sobre la izquierda, bajo la que descansa el báculo. A sus pies el lebrel, con ancho collar liso sujeto con una cadena y con la cabeza vuelta hacia su amo, del mismo tipo de los restantes sepulcros del taller de Ferrand González.

La peana, en la que aparecen incrustados ocho leones, se decora con cuadrilóbulos con escotaduras de forma oblicua, que enmarcan sendos escudos, excepto en los costados correspondientes a la cabeza y los pies donde aparece el escudo en solitario. En realidad, estos blasones se corresponden con otros que aparecen en el claustro de los Laureles ${ }^{25}$.

Entre los escudos existe una decoración de tipo vegetal que responde, como es característico del taller de Ferrand González, a varios tipos: la hoja de roble de bordes lobulados y aserrados, con bellotas, una versión esquemática del pámpano de la vid con pequeños racimos, arabies ${ }^{26} y$ hojas lanceoladas con roleos en los extremos ${ }^{27}$. En el espacio medio del costado correspondiente a la mano derecha del obispo, se encuentran los tallos ondulantes emergiendo de las bocas de animales, al igual que ocurre en el tramo más próximo a los pies, del costado opuesto, mientras en el intermedio brotan de una máscara y una figurilla humana.

A lo largo de los costados, insertos en el friso, sobresalen diversos leones, cuatro en cada cara. Cada uno muestra una actitud diferente, albergando entre sus garras diversas figuras humanas. En el costado derecho, comenzando desde la cabeza hacia los pies, el primer león, que conserva parte se su policromía, mira hacia el que tiene más próximo, mientras con su garra diestra, tira del cabello de lo que podría ser una figura femenina de rostro muy redondeado y labios carnosos, cuya nariz se encuentra, en buena parte mutilada. El segundo león, observa, a su vez, al que le antecede, sujetando entre sus garras una figura de rasgos afines con la anterior, sin que sea posible precisar su sexo. El tercer león, repite el primer modelo, aunque se ha perdido la policromía, mientras el cuarto, se muestra semejante al segundo con dorado en la melena, rojo en el interior de la boca y un tono negruzco en el cabello de la figura humana que se halla prisionera entre sus garras. En el costado izquierdo, el primer león mira hacia arriba, presentando la nariz y la parte superior de la boca mutiladas. Conserva el dorado de la cabellera, parte del rojo en el interior de sus fauces, y sujeta con su garra izquierda una figura humana cuyo cabello parece el de un personaje tonsurado, que semeja un fraile. El segundo, que mira hacia su compañero, posee entre sus garras un personaje con capucha, ¿quizá otro fraile? Por su parte el tercer león, que mira hacia el cuarto, presenta su ojo y oreja izquierdos mutilados, si bien ha conservado parte de la policromía en su melena y boca; sujeta con ambas garras una cabeza humana, cubierta con un turbante, cuyo tamaño es superior al de las restantes figuras y que, a diferencia de ellas, muestra el rostro en posición vertical y no invertido; por su atuendo invoca la imagen del moro, tantas veces representada en la miniatura de la época. Finalmente, el cuarto león, repite el modelo del segundo. Sin duda toda esta galería de personajes, guarda relación con la vulnerabilidad del indi-

\footnotetext{
25 Cuartelado con cruces de brazos iguales en negro sobre blanco - policromía conservada en parte en el central correspondiente a los pies del sepulcro-y castillos en rojos sobre oro, justo al contrario de lo que aún se aprecia en uno de los escudos conrespondientcs a la zona de la cabeza; véase Martínez Caviró, B.: "El mudéjar...", op. cit., p. 384.

26 Hoja de tres lóbulos con bordes rizados y dos pequeños lóbulos rizados junto al tallo.

27 Pérez Higuera, M. T., op. cit., pp. 136-7.
} 
viduo ante el pecado, que le acecha de modo constante, y cuyo triunfo se identifica con la muerte que afecta por igual a toda la humanidad sin respetar razas, sexos, ni condición social.

En conclusión, también el propio sepulcro, al presentar elementos como el cordón franciscano, y pertenecer al taller de Ferrán González, activo en Toledo, entre finales del siglo xIv y la primera década del xv, contribuye a disipar las dudas sobre la adjudicación del sepulcro episcopal existente en Santa Clara de Toledo, al obispo de Lugo, Juan Enríquez. Sus vinculaciones familiares y personales con el convento, por esa misma época, le llevarían a elegirlo como lugar se reposo definitivo, y donde se perpetuase su memoria, si bien su deseo no se cumplió, pues su identidad permaneció durante mucho tiempo, relegada al olvido.

\section{Marta Cendón Fernández Universidad de Santiago de Compostela}

\section{RELIEVES QUE DECORAN LOS PEDESTALES DE LAS ESCULTURAS DE LA REINA CRISTINA DE SUECIA}

La llegada a España de la importante colección de escultura clásica de la reina Cristina de Suecia, adquirida por Felipe V e Isabel de Farnesio en 1724 para el palacio de la Granja, es un tema de sobra conocido y del que últimamente se han hecho eco varias publicaciones así como los catálogos del Museo del Prado (en proceso de edición), que es donde se conserva la gran mayoría de estas piezas ${ }^{1}$.

Conocemos por las descripciones de los inventarios, tanto de la reina, como del príncipe Odescalchi, a quien perteneció la colección desde 1692 a 1713, sobre qué pedestales iban colocadas algunas de las más famosas esculturas y qué relieves los decoraban. Algunos eran clásicos y procedían de otras fomosas colecciones romanas, como la Ludovisi o la del cardenal Camillo Massimi, otros eran modernos, y fueron encargados por el propio Odescalchi a escultores de su tiempo, uno de ellos Pierre Monot 2 .

Ninguno de estos relieves se encuentra con las esculturas en el Museo del Prado aunque, por lo que se ha podido averiguar, algunos permanecen aún en el palacio de la Granja en los pedestales, seguramente originales, que sirven para sustentar las copias en yeso que fueron encargadas en 1746, antes del traslado definitivo de las piezas originales ${ }^{3}$.

\footnotetext{
${ }^{1}$ La bibliografía sobre su vida es abundante. Para una aproximación ver Taylor, F. H., Artistas, príncipes y mercaderes. Barcelona, 1960, pp. 308-17 y el catálogo de la exposición "Christina, Queen of Sweden». Estocolmo, 1966. Existe además una recopilación en la biografía realizada por Quilliet, B., Cristina de Suecia, un rey excepcional. Barcelona, 1993, y en el artículo sobre su faceta coleccionista de Borsellino, E., "Cristina de Svezia collezionista". Ricerche di Storia dell' Arte, n. ${ }^{\circ}$ 54, 1994. Anteriormente, Bulst, W. A., "Die Antiken-Sammlungen der Königin Christina von Schweden", en la Revista de la Universidad de Heildelberg, T. 41, junio de 1967, pp. 121-135, describió cómo estaba instalada la colección y su significado.

2 Pierre-Étienne Monnot (Orchamps-Vennes, Doubs, 1657-Roma, 1733), escultor francés que, después de pasar unos años en París, en el entorno de Versalles, apareció en Roma donde enseguida se introdujo en la colonia de artistas procedentes de su país y recibió muchos encargos. Entre los más importantes se encuentran algunos de los relieves y estatuas del altar de la capilla de San Ignacio en el Gesù, el monumento funerario de Inocencio XI Odescalchi, en la basílica de San Pedro, en el Vaticano, según diseño de Carlo Maratti, las figuras de San Pedro y San Pablo en San Juan de Letrán, así como otras esculturas en Santa María del Popolo y Santa María de la Victoria. Su relación con el príncipe Odescalchi fue intensa convirtiéndose en su escultor favorito.

3 Azcue, L., «Los vaciados en la Real Academia de Bellas Artes de San Fernando, la dinastía Pagniucci». Academia, 2. ${ }^{\circ}$ semestre de 1991, p. 405; León, P., "La colección de escultura clásica del Museo del Prado», en Schröder, S., Catálogo de la Escultura clásica del Museo del Prado, I: Los Retratos. Madrid, 1993, p. 16.
} 